\title{
Physician awareness of elevated cholesterol
}

\author{
MICHAEL B. CLEARFIED, DO \\ STEVE FEDORKO, PhD \\ MARK E. MCKINNEY, PhD
}

Recent studies suggest a heightened awareness of the association between elevated cholesterol and heart disease. Physician awareness of an elevated cholesterol level was investigated at a university-affiliated, 200 -bed community hospital. All cholesterol levels $>240 \mathrm{mg} / \mathrm{dL}$ on a multichemistry profile were evaluated regarding physician awareness. Criteria for awareness included any notation in the patient's chart indicating the physician's recognition of the abnormal cholesterol level or therapeutic intervention (dietary or pharmacologic). During March 1986, an awareness level of $20 \%$ was found. A similar review in March 1988 revealed no change despite a redefinition of the normal laboratory range of serum cholesterol from 133 to $298 \mathrm{mg} / \mathrm{dL}$ to 130 to $240 \mathrm{mg} / \mathrm{dL}$.

On April 12, 1988, a 1-hour lecture sponsored by the Physician Cholesterol Education Program was presented at a hospital general staff meeting. Physician cholesterol awareness rose to $51.6 \%$ for the remainder of April through May 1988, and was $48.3 \%$ at 6-month post-CME followup. Chart reviews showed no heightened physician awareness related to the pa-

From the divisions of general internal medicine and of clinical and educational research, department of medicine, Texas College of Osteopathic Medicine.

Reprint requests to Michael B. Clearfield, DO, division of general internal medicine, department of medicine, Texas College of Osteopathic Medicine, 3500 Camp Bowie, Blvd, Fort Worth, TX 76107-2690. tient's age, sex, or diseases secondarily associated with increased cholesterol; however, increased physician awareness was associated with the primary diagnosis of atherosclerotic vascular disease and severity of hypercholesterolemia. Physician awareness of an elevated serum cholesterol level was poor during two retrospective prevalence surveys but improved considerably after delivery of an educational program.

High cholesterol levels have been associated with increased risk of cardiovascular morbidity and mortality, ${ }^{1,2}$ and the risk rises progressively with increasing levels. ${ }^{3}$ A growing number of studies ${ }^{4-8}$ suggest that lowering the blood cholesterol level will not only lower the risk of coronary disease, but it will also retard atherosclerotic progression in individuals with existing coronary disease. The 1988 report of the National Cholesterol Education Program's Expert Panel includes guidelines for the detection of high blood cholesterol in adults. ${ }^{9}$ These guidelines, formulated by a multidisciplinary panel, are designed to help physicians to identify adults at high risk for coronary artery disease.

It is estimated that as many as 40 million Americans may enter the healthcare system for treatment of elevated cholesterol if these guidelines are followed. These guidelines are based on calculated low-density lipoprotein (LDL) cholesterol levels; however, a screening measurement of total serum cholesterol is the 
initial step. A serum cholesterol level of $\geqslant 240$ $\mathrm{mg} / \mathrm{dL}$ is considered high in the adult population. ${ }^{9}$ For clinical efficacy, it is essential for physicians to become familiar with these guidelines and recommended therapeutic interventions. ${ }^{10,11}$

In our study, physician awareness of a screening cholesterol level of $\geqslant 240 \mathrm{mg} / \mathrm{dL}$ was investigated at a 200 -bed university-affiliated community hospital. The primary objectives of this study were to (1) determine the level of physician recognition of elevated cholesterol in a typical hospital population; (2) determine the effect of a change in the upper limit of normal cholesterol used on laboratory reporting forms on the recognition by physicians of elevated cholesterol in their patients; (3) determine the immediate and 6-month follow-up effects of a hospital-sponsored lecture on cholesterol awareness on the physicians' recognition of elevated cholesterol levels in their patients; and (4) determine if patient age, sex, severity of elevated cholesterol, or primary diagnosis predisposes the physician to respond to an elevated cholesterol level.

\section{Patients and methods}

Physicians' clinical responses to hospital patients' elevated cholesterol levels were assessed before and after (1) redefining the clinically normal range of serum cholesterol on laboratory report forms and then (2) presenting a continuing medical education (CME) lecture on hypercholesterolemia.

A study population of 402 inpatients at Fort Worth (Texas) Osteopathic Medical Center was drawn from a review of approximately 3400 charts. All cholesterol levels $>240 \mathrm{mg} /$ dL during the months of March 1986 and March, April, May, October, and November 1988 were examined for inclusion in the study population. The cholesterol measurements were obtained from a screening multichemistry profile by use of a Beckman Astra Analyzer. Patients were excluded from review if their diagnosis included terminal disease state or severe dementia, or if they were in "do not resuscitate"status. Cholesterol measurements of 502 patients from March 1986 were reviewed, with 92 meeting criteria; 742 choles- terol measurements from March to April 12, 1988, were reviewed, with 97 meeting criteria; 800 cholesterol measurements from April 12 through May 25, 1988, were reviewed, with 91 meeting criteria; and 1355 cholesterol measurements from October and November 1988 were reviewed, with 122 meeting criteria.

The laboratory form in March 1986 reported as normal serum cholesterol levels in the range from 133 to $298 \mathrm{mg} / \mathrm{dL}$. Patients' charts that met inclusion criteria during this period provided preintervention data. In late March 1988, the hospital laboratory form was changed to indicate a redefinition of the normal range for serum cholesterol from 133 to $298 \mathrm{mg} / \mathrm{dL}$ to a range of 130 to $240 \mathrm{mg} / \mathrm{dL}$. Of the 97 subjects reviewed during March and early April 1988, 48 had laboratory reports using $298 \mathrm{mg} / \mathrm{dL}$ as the upper limit of normal, while 49 had forms using $240 \mathrm{mg} / \mathrm{dL}$ as the upper limit of normal. This change in the laboratory form's definition of normal served as the first intervention.

A 1-hour lecture sponsored by the National Cholesterol Education Task Force was given to the medical staff on April 12, 1988. This educational program reviewed risks of cardiovascular morbidity and mortality and the $\mathrm{Na}$ tional Cholesterol Education Program Expert Panel's published guidelines for the detection of high blood cholesterol in adults. Also presented during the program were national levels of physician awareness of elevated cholesterol as well as comparable levels of awareness observed at the hospital in this study. This CME program constituted the second intervention. Patient data from chart reviews from October and November 1988 served as 6-month post-CME follow-up data.

Criteria for awareness included any notation in the chart indicating the physician's recognition of the abnormal cholesterol level or any recommendation for therapeutic intervention (dietary or pharmacologic). Data were collected to compare the level of physician awareness from 1986 to 1988 before and after the laboratory's change in definition of normal cholesterol values, as well as before and after the CME lecture (immediate and follow-up). Chart data were reviewed to see if a heightened aware- 
ness of an increased cholesterol level was related to the patient's age, sex, severity of elevated cholesterol, and history of atherosclerotic disease, diabetes, hypothyroidism, or nephrotic syndrome.

All percentages were compared by use of the method of Bruning and Kintz. ${ }^{12}$ Each comparison yielded a $z$ score, which was compared with the normal distribution using a two-tailed test of significance. An $\alpha$ level of .05 was adopted as the level of significance.

\section{Results}

Physician awareness of elevated cholesterol was $19.6 \%$ in March 1986 (Figure). Prior to the laboratory's changing the upper limit of normal value from $298 \mathrm{mg} / \mathrm{dL}$ to $240 \mathrm{mg} / \mathrm{dL}$, data from March 1988 revealed a physician awareness level of $22.9 \%$. In mid-March, a new upper limit normal of $240 \mathrm{mg} / \mathrm{dL}$ was instituted for cholesterol, and the level of aware- ness from this date through April 12 was 20.4\%. On April 12, 1988, the CME lecture was presented at a hospital general staff meeting. Physician cholesterol awareness for the remainder of April through May 25 was $51.6 \%$ (significantly different from all other pre-CME times, $P<.01$ ). In addition, at the 6 -month follow-up assessment, physician cholesterol awareness had held steady at $48.3 \%$ (significantly different from all other pre-CME times, $P<.01$, and not significantly different from the preliminary post CME-data from April and May 1988).

Overall, physician awareness of elevated cholesterol levels was observed in 145 of 402 cases (36.1\%). Data comparing physician awareness of elevated cholesterol in relation to the patient's sex, age, severity of cholesterolemia, and primary diagnoses are outlined in the.Table. No statistically signficant difference was found for patient sex compared with physician

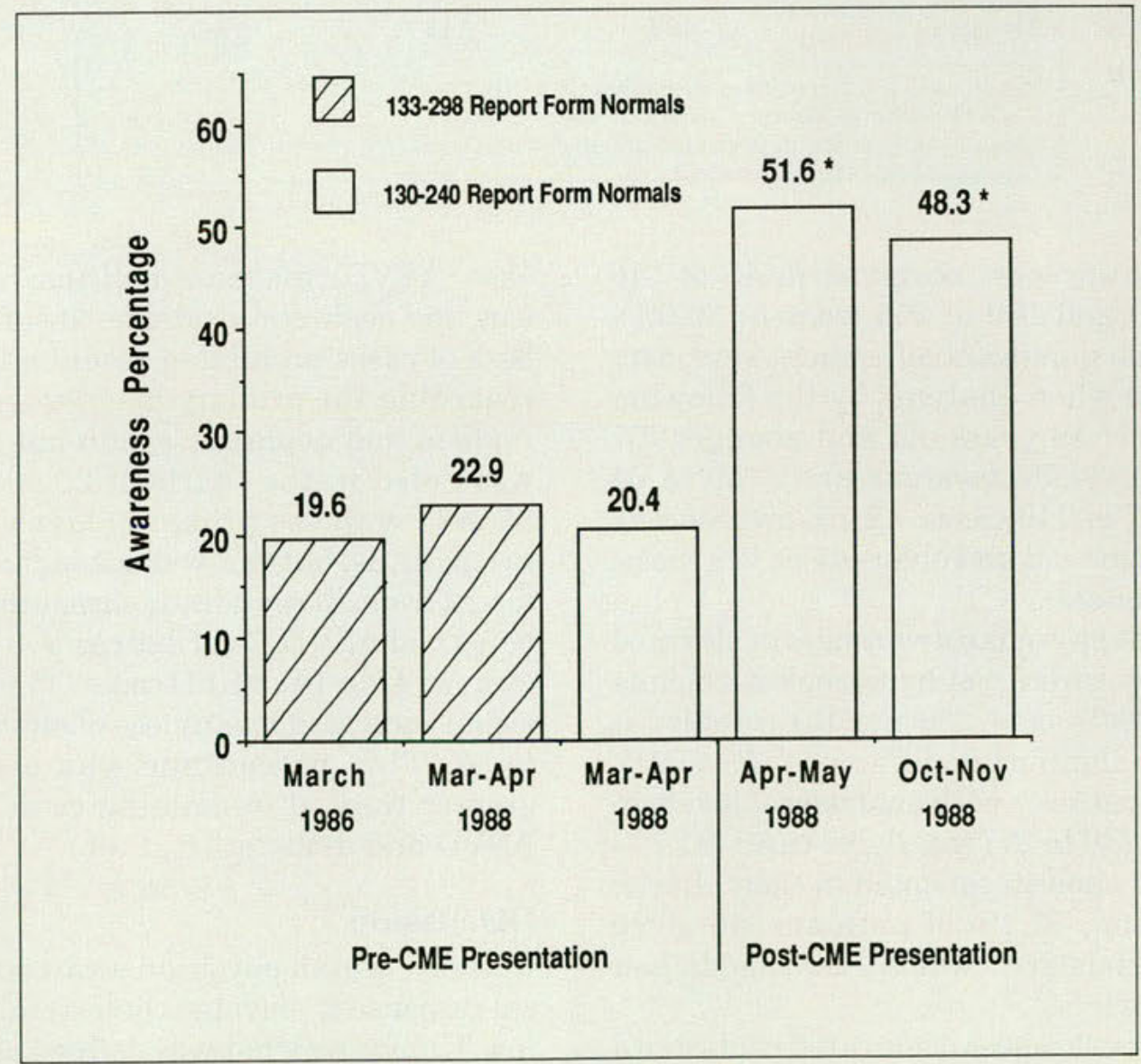

Figure. Physician awareness of elevated cholesterol. *Significantly different from each and all pre-CME times $(P<.01)$. 


\begin{tabular}{|c|c|c|c|}
\hline \multicolumn{4}{|c|}{$\begin{array}{c}\text { Table } \\
\text { Comparison of Physician Awareness of Elevated Cholesterol by } \\
\text { Patient's Sex, Age, Severity, and Primary Diagnosis }\end{array}$} \\
\hline Variable & $\begin{array}{c}\text { No. } \\
\text { of } \\
\text { cases }\end{array}$ & $\begin{array}{l}\text { No. with } \\
\text { noted } \\
\text { cholesterol }\end{array}$ & $\begin{array}{c}\text { Physician } \\
\text { awareness, } \\
\%\end{array}$ \\
\hline \multicolumn{4}{|l|}{ Sex } \\
\hline Male & 146 & 45 & 30.8 \\
\hline Female & 256 & 100 & 39.0 \\
\hline \multicolumn{4}{|l|}{ Age } \\
\hline$\leqslant 49$ & 163 & 57 & 34.9 \\
\hline $50-64$ & 110 & 47 & 42.7 \\
\hline$\geqslant 65$ & 129 & 41 & 31.7 \\
\hline \multicolumn{4}{|l|}{ Severity } \\
\hline $240-297 \mathrm{mg} / \mathrm{dL}$ & 312 & 99 & $31.7^{*}$ \\
\hline$\geqslant 298 \mathrm{mg} / \mathrm{dL}$ & 90 & 46 & $51.1^{*}$ \\
\hline \multicolumn{4}{|l|}{ Diagnosis } \\
\hline ASVD & 107 & 47 & $43.9 \ddagger$ \\
\hline Diabetes & 66 & 25 & 37.8 \\
\hline All others & 229 & 73 & $31.8 \div$ \\
\hline \multicolumn{4}{|l|}{ TOTALS } \\
\hline All cases & 402 & 145 & 36.1 \\
\hline $\begin{array}{l}\text { *Significantly di } \\
\text { †SVD = ather } \\
\ddagger \text { Significantly d }\end{array}$ & $\begin{array}{l}\text { each oth } \\
\text { iscular dis } \\
\text { n each oth }\end{array}$ & $\begin{array}{l}01) . \\
.05) \text {. }\end{array}$ & \\
\hline
\end{tabular}

cholesterol awareness observed in 45 of 146 men $(30.8 \%)$ and 100 of 256 women (39.0\%). In addition, no significant differences were identified for age when analyzed by the following categories: (1) 49 years old and younger (57 of 163 cases, $34.9 \%$ awareness); (2) 50 to 64 years old (47 of 110 cases, $42.7 \%$ awareness); and (3) 65 years old and older (41 of 129 cases, $31.7 \%$ awareness).

Analysis of physician awareness of elevated cholesterol by severity of hypercholesterolemia $(240-297 \mathrm{mg} / \mathrm{dL}$ vs $\geqslant 298 \mathrm{mg} / \mathrm{dL})$ revealed a statistically significant difference $(P<.01)$. For the 312 patients with cholesterol levels in the range of 240 to $297 \mathrm{mg} / \mathrm{dL}, 99$ cases $(31.7 \%)$ had elevated cholesterol noted in their charts. In comparison, $51.1 \%$ of patients (46 of 90 cases) with cholesterol levels $\geqslant 298 \mathrm{mg} / \mathrm{dL}$ had such a notation.

Physician awareness of elevated cholesterol was also examined in regard to differing primary diagnoses of atherosclerotic vascular dis- ease (ASVD), diabetes mellitus, hypothyroidism, and nephrotic syndrome. Insufficient numbers of cases prohibited meaningful analyses regarding the primary diagnoses of hypothyroidism and nephrotic syndrome. Cholesterol was noted in the charts of 25 of 66 patients $(37.8 \%)$ with the primary diagnosis of diabetes mellitus, but this was not significantly different from all remaining cases other than diabetes and ASVD ( 73 of 229 cases, $31.8 \%$ ). However, in 47 of 107 ASVD cases (43.9\%), the physician indicated awareness of elevated cholesterol. This percentage was significantly greater than all remaining cases other than ASVD and diabetes $(P<.05)$.

\section{Discussion}

Initially, overall physician awareness and clinical response to elevated cholesterol levels were low. Changing what was defined as the abnormally elevated cholesterol level had minimal impact on physician awareness; however, a 
CME lecture on the recognition and treatment of elevated cholesterol significantly increased physician awareness. Six-month post-CME follow-up indicated no significant decline in overall level of physician response to hypercholesterolemia.

The patient's age and sex had no significant impact on physician clinical response. However, greater physician awareness of elevated cholesterol was observed in relation to increased severity of hypercholesterolemia. Diagnoses related to atherosclerosis were significantly associated with increased physician clinical response. Although diabetes mellitus is a concurrent cardiovascular risk factor, its presence as a primary diagnosis did not affect physician clinical response to elevated cholesterol levels. It is particularly important to observe that even after CME efforts, only about half of the patients with a cholesterol level > $240 \mathrm{mg} / \mathrm{dL}$ had any notation in their charts that indicated physician awareness of an elevated cholesterol level.

The baseline survey in 1986 was conducted after the Consensus Conference by the $\mathrm{Na}$ tional Institutes of Health on Lowering Blood Cholesterol $^{6}$ as well as from the Lipid Research Clinics (LRC) Coronary Primary Prevention Trial $(\mathrm{CPPT})^{7}$ that linked the reduction in serum cholesterol with the reduction in incidence of fatal and nonfatal coronary events. The second screening period in 1988 was conducted after the Report of the National Cholesterol Education Program Expert Panel,${ }^{9}$ which modified the earlier recommendations.

Two additional studies in 1987, the Helsinki Heart Study ${ }^{13}$ and the Cholesterol Lowering Atherosclerosis Study (CLAS), ${ }^{5}$ also confirmed the beneficial effect of lowering the serum cholesterol level in the treatment of coronary heart disease. It is apparent that this new information did not change overall physician awareness of an isolated elevated cholesterol level. This awareness also was not affected by a change in the definition of high cholesterol from $>298 \mathrm{mg} / \mathrm{dL}$ to $>240 \mathrm{mg} / \mathrm{dL}$, which occurred in mid-March 1988.

Recent studies have shown that there is an increasing awareness of elevated cholesterol levels from both the public ${ }^{14}$ and the physi- cian perspective. ${ }^{15}$ In a study sponsored by the National Heart, Lung and Blood Institute, ${ }^{15}$ $64 \%$ of practicing physicians surveyed nationally via telephone in 1986 thought that a reduction of blood cholesterol levels would reduce coronary artery disease compared with $39 \%$ of physicians surveyed in 1983 . In several studies examining cholesterol awareness in a family practice residency program, the level of awareness ranged from $5 \%$ to $8 \% .^{16-18}$

In another study screening New York metropolitan area residents for elevated serum cholesterol, ${ }^{10}$ no action was recommended in the majority of cases in which an elevated level was noted and the patient's physician was consulted for advice. One study ${ }^{19}$ showed that even among patients hospitalized for coronary heart disease before age 60 years, a lipid profile had been ordered for only $18 \%$. Also, only $53 \%$ of these patients had any notation of the presence or absence of a lipid abnormality in their charts, as compared with $44 \%$ of patients in our study, which incorporated the diagnosis of atherosclerotic disease under the coronary artery disease classification.

The San Antonio Heart Study ${ }^{20}$ not only revealed a low level of awareness $(7 \%-17 \%)$ of elevated cholesterol, but it also found that only $24 \%$ to $27 \%$ received any therapy, and effective control was achieved in only $39 \%$ to $41 \%$ of those receiving therapy. Our study demonstrated a similarly low level of physician awareness of an elevated cholesterol level.

As previously noted, other studies ${ }^{19,21}$ report that the diagnosis of associated atherosclerotic disease does not appear to increase the likelihood of a physician's awareness of an elevated cholesterol level, even when the cholesterol level is markedly elevated $(>350 \mathrm{mg} / \mathrm{dL}){ }^{22}$ In contrast, our present study indicated that greater elevated cholesterol levels were associated with increased physician awareness. It appears, however, that a diagnosis of diabetes does not have the same impact. Although the American Diabetes Association (ADA) currently recommends a diet low in cholesterol and saturated fats aimed at reducing the serum cholesterol level, this recommendation frequently is not followed.

In addition, a 1987 Consensus Development 
Conference on Diet and Exercise in non-insulin-dependent diabetes mellitus ${ }^{23}$ raised doubts about recommending high-carbohydrate/lowfat diets to all patients with diabetes. In fact, several studies ${ }^{24,25}$ suggest that certain diets recommended by the ADA may have a potentially harmful effect on lipoprotein levels. Therefore, the degree of awareness of an elevated cholesterol level should be heightened rather than decreased when such an elevation is associated with diabetes mellitus. One may assume that physicians frequently consider dietary and pharmacologic intervention for diabetes sufficient to resolve the cholesterol abnormality.

Finally, the marked increase in physician awareness after a 1-hour lecture sponsored by the Physician Cholesterol Education Program did not decay significantly at a 6 -month followup evaluation. The increased awareness of the immediate post-CME period did decrease slightly at 6-month follow-up, and further evaluation is needed to determine if the increased awareness would hold steady at higher levels, rather than returning to baseline values, over a longer follow-up period.

The authors acknowledge the assistance of the pathology department and the medical records department, Ft Worth Osteopathic Medical Center.

1. Castelli WP, Garrison RJ, Wilson PW, et al: Incidence of coronary heart disease and lipoprotein cholesterol levels. The Framingham Study. JAMA 1986;256:2835-2838.

2. Kromhout D, Bosschieter EB, Drijver M, et al: Serum cholesterol and 25-year incidence of and mortality from myocardial infarction and cancer. The Zutphen Study. Arch Intern Med 1988;148:1051-1055.

3. Stamler J, Wentworth D, Neaton JD: Is relationship between serum cholesterol and risk of premature death from coronary heart disease continuous and graded? Findings in 356,222 primary screenees of the Multiple Risk Factor Intervention Trial (MRFIT). JAMA 1986;256:2823-2828.

4. Duffield RGM, Lewis B, Miller NE, et al: Treatment of hyperlipidemia retards progression of symptomatic femoral atherosclerosis. A randomised controlled trial. Lancet 1983;2639642.

5. Blankenhorn DH, Nessim SA, Johnson RL, et al: Beneficial effects of combined colestipol-niacin therapy on coronary atherosclerosis and coronary venous bypass grafts. JAMA $1987 ; 257: 3233-3240$.
6. Consensus conference. Lowering blood cholesterol to prevent heart disease. JAMA 1985;253:2080-2086.

7. The Lipid Research Clinics Coronary Primary Prevention Trial results: I. Reduction in incidence of coronary heart disease. JAMA 1984;251:351-364.

8. Arntzenius AC, Kromhout D, Barth JD, et al: Diet, lipoproteins, and the progression of coronary atherosclerosis: The Leiden Intervention Trial. N Engl J Med 1985;312:805-811.

9. Report of the National Cholesterol Education Program Expert Panel on Detection, Evaluation, and Treatment of High Blood Cholesterol in Adults. The Expert Panel. Arch Intern Med 1988;148:36-69.

10. Wynder EL, Field F, Haley NJ: Population screening for cholesterol determination: A pilot study. JAMA 1986;256:28392842.

11. Landzberg JS, Heim CR: Physician recognition and treatment of hypercholesterolemia. Arch Intern Med 1989;149:933935.

12. Bruning JL, Kintz BL: Computational Handbook of Statistics. Glenview, Ill, Scott, Foresman \& Co, 1968, pp 199-200.

13. Frick MH, Elo O, Haapa K, et al: Helsinki Heart Study: Primary-prevention trial with gemfibrozil in middle-aged men with dyslipidemia. Safety of treatment, changes in risk factors, and incidence of coronary heart disease. N Engl J Med 1987;317:1237-1245.

14. Schucker B, Bailey K, Heimbach JT, et al: Change in public perspective on cholesterol and heart disease. Results from two national surveys. JAMA 1987;258:3527-3531.

15. Schucker B, Wittes JT, Cutler JA, et al: Change in physician perspective on cholesterol and heart disease. Results from two national surveys. JAMA 1987;258:3521-3526.

16. Mandel IG, Franks P, Dickinson JC: Screening guidelines in a family medicine program: A 5 year experience. J Fam Pract 1982;14:901-907.

17. Otradovec K, Blake RL, Parker BM: An assessment of the practice of preventive cardiology in an academic health center. J Fam Pract 1985;21:125-129.

18. Morris PD, Morris ER: Family practice residents' compliance with preventive medicine recommendations. Am J Prevent Med 1988;4:3161-165.

19. Boekeloo BO, Becker DM, LeBailly A, et al: Cholesterol management in patients hospitalized for coronary heart disease. $\mathrm{Am}$ $J$ Prevent Med 1988;4(3):128-132.

20. Pugh JA, Stern MP, Haffner SM, et al: Detection and treatment of hypercholesterolemia in a biethnic community, 19791985. J Gen Intern Med 1988;3:331-336.

21. Ahrens EH Jr: The diet-heart question in 1985: Has it really been settled? Lancet 1985;1:1085-1087.

22. Nash DT: Hypercholesterolemia during hospitalization. Postgrad Med 1986;79(2):303-310.

23. National Institutes of Health: Consensus Development Conference on Diet and Exercise in Non-Insulin Dependent Diabetes Mellitus. Diabetes Care 1987;10:639-644.

24. Garg A, Bonanome A, Grundy SM, et al: Comparison of a high-carbohydrate diet with a high-monosaturated-fat diet in patients with non-insulin-dependent diabetes mellitus. $N \mathrm{Engl}$ J Med 1988;319:829-834.

25. Coulston AM, Hollenbeck CB, Swislocki ALM, et al: Deleterious metabolic effects of high carbohydrate, sucrose containing diets in patients with non-insulin-dependent diabetes mellitus. Am J Med 1987;82:213-220. 